\title{
Economic and epidemiological impact of different intervention strategies for clinical contagious mastitis
}

\author{
Maya Gussmann, ${ }^{1 *}$ Wilma Steeneveld, ${ }^{2}$ Carsten Kirkeby, ${ }^{1}$ Henk Hogeveen, ${ }^{2,3}$ Mirjam Nielen, ${ }^{2}$ Michael Farre, ${ }^{4}$ \\ and Tariq Halasa ${ }^{1,5}$ \\ ${ }^{1}$ Epidemiology Group, National Veterinary Institute, Technical University of Denmark, 2800 Kgs. Lyngby, Denmark \\ ${ }^{2}$ Department of Farm Animal Health, Faculty of Veterinary Medicine, Utrecht University, 3584 CL Utrecht, the Netherlands \\ ${ }^{3}$ Business Economics Group, Department of Social Sciences, Wageningen University, 6706 KN Wageningen, the Netherlands \\ ${ }^{4}$ SEGES Livestock Innovation, 8200 Aarhus, Denmark \\ ${ }^{5}$ Section of Animal Welfare and Disease Control, Department of Large Animal Sciences, Copenhagen University, 1870 Frederiksberg, Denmark
}

\section{ABSTRACT}

The overall aim of this study was to compare different intervention strategies for clinical intramammary infections (IMI). We conducted a simulation study to represent a Danish dairy cattle herd with IMI caused mostly by Staphylococcus aureus and 9 different intervention strategies for clinical IMI. A standard intervention of $3 \mathrm{~d}$ of treatment consisting of intramammary injections for all clinical cases was used. Two of the strategies reflected the use of more antibiotics and 6 strategies reflected cow-specific treatment or culling decisions. For these strategies, we assessed the cost and effectiveness of culling as an IMI intervention. Our results showed that nearly all strategies could reduce the number of IMI cases [e.g., a median of 37 clinical cases with the extended intramammary treatment over 5 d strategy (Basic5) and 30 clinical cases with the cow culled with recovery probability below 50\% (Before50)] compared with the standard intervention (median of 42 clinical cases). This happened alongside either increased antibiotic usage (e.g., from a median of 123 treatment days up to 179 treatment days with strategy Basic5) or an increased number of cows culled in relation to IMI (e.g., from a median of 16 up to 24 cows with strategy Before50). Strategies with more antibiotics or reactive culling had a slightly higher net income (e.g., €190,014 median net income with strategy Basic5 or $€ 196,995$ with strategy Before50 compared with €187,666 with the standard strategy). This shows that a cow-specific clinical intervention approach can be cost-effective in reducing IMI incidence.

Key words: treatment, culling, cow-specific, simulation model

Received April 18, 2018.

Accepted October 3, 2018.

*Corresponding author: makg@sund.ku.dk

\section{INTRODUCTION}

Mastitis, or IMI, is frequently found on dairy farms. It causes considerable economic losses (Halasa et al., 2007), impairs animal welfare (Broom, 1991; von Keyserlingk et al., 2009), and is one of the main reasons for the use of antibiotics in dairy cattle in Denmark (DANMAP, 2016; EMA and EFSA, 2017).

Costs related to clinical IMI can be divided into those associated with treatment, costs from increased mortality through culling (i.e., replacement of culled animals), and indirect costs from production losses (Halasa et al., 2007), all of which have previously been investigated in several studies (e.g., Bar et al., 2008). Those studies relied on a modeling approach in which a farm with IMI was simulated and the resulting costs were calculated. Some previous studies focused on modeling the occurrence or transmission of IMI-causing pathogens (Allore et al., 1998; Østergaard et al., 2005; Hagnestam-Nielsen and Østergaard, 2009; Halasa et al., 2009a), whereas others investigated intervention (Steeneveld et al., 2011; Halasa, 2012) or replacement strategies (Cha et al., 2014). Many of those studies also took into account the IMI-causing pathogen, and are thus pathogen-specific (Allore et al., 1998; Østergaard et al., 2005; Halasa et al., 2009a), as the effects of an IMI (e.g., milk production losses) may depend on the causative pathogen (Gröhn et al., 2004; Hertl et al., 2014).

Intervention strategies investigated for clinical cases usually consist of (mainly intramammary) antibiotic treatment. However, in the light of rising consumer awareness regarding antibiotic usage in food animals and its connection with antimicrobial resistance (Ruegg, 2003), it may be prudent to search for alternative intervention strategies. For instance, culling cows with clinical mastitis could be a valid alternative. In contrast to antibiotic treatment, however, culling of infected ani- 
mals is rarely considered as an intervention strategy for IMI, but rather as a possible consequence (Halasa and Hogeveen, 2018). Culling was studied in the context of optimal replacement decisions (Heikkilä et al., 2012; Cha et al., 2014), where it led to only a slightly earlier optimal replacement time for cows with clinical IMI; therefore, treatment was recommended over culling in most cases. Previous studies evaluated the optimal replacement time in economic terms, comparing results for cows with and without IMI; however, to the best of our knowledge, specific culling strategies for clinical IMI have not yet been the focus of any study.

In addition to antibiotic treatment or culling of cows with clinical mastitis, it may also be economically beneficial to reduce the transmission of IMI-causing pathogens; for instance, by improving hygiene or biosecurity. However, if pathogen transmission is contagious, the number of new cases depends on the number of infected animals (Halasa et al., 2009a). Reducing the transmission of IMI-causing pathogens may therefore lead to a long-term indirect cost reduction due to a decreased number of new cases (Steeneveld et al., 2011). Consequently, the long-term effects of reducing transmission must be evaluated with a model that includes transmission dynamics, as in the study by Halasa (2012).

The aim of the current study was to evaluate different IMI intervention strategies for clinical contagious mastitis using 2 distinct approaches (more antibiotics and reactive culling). For this purpose, cow- and pathogen-specific IMI transmission were modeled for a Danish dairy cattle herd with 200 dairy cows. Strategies, including cow-specific antibiotic treatment of clinical cases and culling of individual cows with clinical IMI, were compared for farm economic and epidemiological parameters, including the number of clinical IMI cases, culled cows, and antibiotic doses (treatment days).

\section{MATERIALS AND METHODS}

\section{Herd and Transmission Model}

Herd Model. The model we used was the MiCull (Mastitis-iCull) model, version 2.0. The original MiCull model, version 1.0 (Gussmann et al., 2018b), was used in Kirkeby et al. (2017) and differs only in the possible interventions for clinical IMI, which are new in version 2.0, as explained below. The model and all simulations were programmed and run in the statistical computing software R version 3.2.2 "Fire Safety" (R Core Team, 2015). Figures were created using the package ggplot2 (Wickham, 2009).

In the model, a dairy herd with 200 cows was simulated in single-day time steps (Kirkeby et al., 2016). The cows were distributed over 5 compartments (calves, heifers, lactating cows, dry cows, and calving cows). After a stochastically determined number of days, each cow moved on to the next compartment unless culled. Feeding depended on the compartment, and, for lactating cows, the produced milk was taken into account. Lactation (milk, protein, and fat) and SCC curves were cow-specific (Græsbøll et al., 2016) and adjusted for IMI effects, such as increased SCC (Schepers et al., 1997; Wilson et al., 1997) and decreased milk yield (Hortet et al., 1999; Gröhn et al., 2004). Milk from clinically affected cows was discarded during antibiotic treatment and for the following $6 \mathrm{~d}$. The milk yield and SCC were recorded once per month. The future average milk production (FAP) of a cow was estimated (Græsbøll et al., 2017). Model parameters can be found in Table 1.

Transmission Framework. The model included 5 pathogen strains that can cause IMI: contagious Staphylococcus aureus, environmental Escherichia coli, both contagious and an environmental Streptococcus uberis, and Streptococcus agalactiae with both contagious and environmental elements combined. Other pathogens were not included due to missing parameters. Transmission parameters are shown in Table 1 and Supplemental Table S1 (https://doi.org/10.3168/jds.2018 -14939). Median daily number of heifers and cows per strategy is shown in Supplemental Table S2 (https:// doi.org/10.3168/jds.2018-14939). The IMI transmission module was adapted and extended from Halasa et al. (2009a, 2010). Heifers were modeled separately from the lactating herd until they calved, at which point they had a certain probability of entering their first lactation in an infected state. For new infections in lactating cows, the infection probability was calculated for every noninfected quarter; this probability was determined by the active pathogen strains, the number of infected quarters for contagious strains, and the susceptibility of the cow. The susceptibility of a cow takes into account risk factors, such as parity and previous IMI (Zadoks et al., 2001), and adjusts susceptibility relative to previously uninfected primiparous cows. There is a pathogen-specific probability for every new infection to immediately appear as a clinical case, otherwise it will be subclinical (Halasa et al., 2009a). Furthermore, previously infected quarters have a certain pathogenspecific probability for spontaneous recovery from the subclinical state or to flare up from subclinical to clinical. Clinical quarters are treated with a 3-d antibiotic intramammary injection, after which the clinical quarter will return to either susceptible or subclinical status (see Table 2), depending on the recovery probability of the individual cow (Steeneveld et al., 2011).

If a cow had a clinical IMI during lactation or a high SCC (200,000 or higher) at 1 of the last 3 monthly 
Table 1. Prices used in the model to calculate income (positive values) and costs (negative values)

\begin{tabular}{lcl}
\hline Item & $\begin{array}{c}\text { Price } \\
(€)\end{array}$ & Reference \\
\hline $1 \mathrm{~kg}$ of protein & 5.8132 & www.arla.dk, September 2017 \\
$1 \mathrm{~kg}$ of fat & 4.1519 & www.arla.dk, September 2017 \\
Handling of $1 \mathrm{~kg}$ of milk & -0.01343 & www.arla.dk, September 2017 \\
Slaughter value per cow & 483 & Kudahl et al. (2007) \\
Feeding & -0.0026 & Kirkeby et al. (2016) \\
Per calf per day & -0.9311 & Kirkeby et al. (2016) \\
Per heifer/dry cow per day & -0.1947 & Kirkeby et al. (2016) \\
Per ECM & -11.10 & Michael Farre (SEGES, Aarhus, Denmark, personal communication) \\
Treatment (per day) & -6.66 & Halasa et al. (2009a); Michael Farre (SEGES, Aarhus, Denmark, personal \\
Opportunity cost (per case per day) & -9.60 & communication) \\
& -12 & Michael Farre (SEGES, Aarhus, Denmark, personal communication) \\
Dry cow treatment & -13.3 & Michael Farre (SEGES, Aarhus, Denmark, personal communication) \\
Bacterial culture & & \\
PCR &
\end{tabular}

recordings, a pooled milk sample was sent for testing by PCR (sensitivity and specificity are given in Table 2) before drying off. Cows with a positive PCR test result received antibiotic dry cow treatment, whereas cows with a negative result were dried off without dry cow treatment. New infections can occur during the first and last week of the dry period, but infection probability does not depend on the number of infected quarters and is lower for cows that received dry cow treatment (Halasa et al., 2009b). Similarly, subclinical cases can only flare up to become clinical cases in the first and last week of the dry period for cows without dry cow treatment. Cows that become clinical cases in the first week will also receive dry cow treatment. Spontaneous recovery can occur throughout the entire dry period (Halasa et al., 2010).

Culling. Cows were evaluated for culling once a week if the number of lactating and dry cows exceeded the target count of 200 dairy animals (Kirkeby et al., 2016). All cows received weighted flags for low milk yield, parity, reproduction status, high SCC, and previous cases of clinical IMI, and those with the highest weightings were culled. There was also a certain probability that some cows would have to be culled for other reasons, such as lameness (Kirkeby et al., 2016). This involuntary culling took precedence over voluntary culling. The cost of culling was around $€ 1,000$ per cow (i.e., the price of a new heifer), not including the income from slaughter. However, the mean slaughter value was deducted for every culled cow, resulting in a cost of less than $€ 1,000$ each.

\section{Intervention Strategies for Clinical IMI}

We simulated a Danish dairy cattle herd with a default yearly median cumulative clinical incidence of about $21 \%$ at cow level, mostly caused by Staph. aureus.

Default Treatment for All Cows. The default intervention in the model for clinical IMI was intramammary treatment over $3 \mathrm{~d}$ (Basic3). The second strategy

Table 2. Model parameters for the main causative pathogen Staphylococcus aureus during lactation

\begin{tabular}{llll}
\hline Parameter & Description & Value & Reference \\
\hline Transmission rate & $\begin{array}{l}\text { Daily rate for susceptible quarters entering infected } \\
\text { state }\end{array}$ & 0.0009 & Fitted value \\
Probability of clinical state & $\begin{array}{l}\text { Probability of a quarter entering clinical state upon } \\
\text { infection }\end{array}$ & 0.17 & Supplemental Table S1 \\
& $\begin{array}{l}\text { Daily probability of a subclinical quarter becoming } \\
\text { clinical }\end{array}$ & 0.0081 & Supplemental Table S1 \\
Flare up probability & $\begin{array}{l}\text { Daily probability of a subclinical quarter becoming } \\
\text { susceptible (without treatment) }\end{array}$ & 0.0064 & Supplemental Table S1 \\
Spontaneous recovery probability & Probability of a clinical quarter becoming susceptible & 0.4 & Supplemental Table S1 \\
Recovery probability & after treatment for bacterial culture & 0.523 & Mahmmod et al. (2013) \\
Test sensitivity & Test sensitivity for & 0.908 & Mahmmod et al. (2013) \\
Test specificity & Test sensitivity for PCR (used at drying off) & 0.895 & Mahmmod et al. (2013) \\
Probability of identifying pathogen & Test specificity for PCR (used at drying off) & 0.988 & Mahmmod et al. (2013) \\
Probability of identifying causative pathogen by PCR & 0.85 & Taponen et al. (2009) &
\end{tabular}

${ }^{1}$ https://doi.org/10.3168/jds.2018-14939. 
consisted of an extended intramammary treatment over $5 \mathrm{~d}$ (Basic5). In the following strategies, treatment was always $3 \mathrm{~d}$ of intramammary treatment, unless specified otherwise.

Longer Treatment for High-Producing Cows. As described above, the FAP was used to determine cows in the top $25 \%$ of expected future milk production. In this strategy (Longer), cows were treated for 5 instead of the usual $3 \mathrm{~d}$.

Culling of Repeated Clinical IMI Cases. In this strategy, cows with clinical IMI for the second time in their current lactation (Repeated) were culled instead of treated.

Testing Before Treatment. In these strategies, clinical cases were not immediately treated. Instead, a milk sample of the new clinically affected quarter was sent for testing by PCR with $85 \%$ probability of identifying the causative pathogen, as described by Taponen et al. (2009). Test results were returned after 1 $\mathrm{d}$ and were used to calculate the expected probability of recovery based on the causative pathogen, history of IMI, parity, DIM, and SCC at the last monthly milk recording (Steeneveld et al., 2011). If the pathogen could not be identified, a mean base cure probability representing an average pathogen was used instead of the cure probability for the actual causative pathogen. The estimated recovery probability was used to decide whether a cow should be culled [recovery probability below $50 \%$ (Before 50 ) or $75 \%$ (Before 75 )] or treated.

Culling with Exceptions. With the Before75 strategy, the farmer may also decide not to cull a certain group of cows; for example, cows in the top 25\% according to the FAP (notCullTop) or cows that are more than approximately 4 mo pregnant (notCullPregnant). These cows were always treated without sending a milk sample for testing.

Testing After Treatment. In a similar way to the testing before treatment strategy, quarters were tested by bacterial culture $7 \mathrm{~d}$ after treatment ended (After). Test sensitivity and specificity were 0.523 and 0.895 , respectively (Mahmmod et al., 2013). If the test result was positive when it returned $1 \mathrm{~d}$ later, the cow would be culled.

\section{Simulations and Model Output}

For each of the 9 strategies described, we ran 500 iterations for a period of $5 \mathrm{yr}$ with an additional 5-yr burn-in time to ensure stable results (see Gussmann et al., 2018b), which described the effect of the strategies rather than the initial parameter values (transmission parameters are given in Table 2).

Model output was collected in the simulated 5-yr period and included economic factors such as income from milk (calculated from the fat and protein price, a milk handling fee, and a penalty or bonus depending on the bulk tank SCC), costs related to IMI (testing, treatment including opportunity costs, culling, dry cow treatment), and other costs (culling with a high SCC or history of IMI, feed). Prices are given in Table 1. These costs were subtracted from the income from milk to calculate a mean (over 5 yr) yearly income for the farm, from which additional expenses (e.g., costs related to other diseases or running costs) had not yet been deducted. The output also included epidemiological parameters, such as the number of clinical cases (quarters entering a clinical state from a susceptible or subclinical state), the number of subclinical cases (quarters entering a subclinical state from a susceptible or clinical state), the number of culled cows (due to IMI intervention, or with a high SCC or history of IMI), and the number of treatment days (e.g., 3-d treatment of a clinical quarter equals 3 treatment days) over the simulated 5-yr period. The numbers were rounded to integers or, in the case of percentages, to one decimal place.

\section{Sensitivity Analyses}

Sensitivity analyses were performed for different parameters (Table 3). These included (1) diagnostic test characteristics [the probability of identifying the pathogen according to Taponen et al. (2009), or the test sensitivity and specificity according to Cederlöf et al. (2012)]; (2) the base cure probability after treatment; (3) the fat and protein prices for 2017 in Denmark (www.arla.dk/om-arla/ejere/arlapris/2017); (4) prices for culling; and (5) transmission rates and causative pathogens (reflecting different herds).

\section{RESULTS}

All results for the strategies we used can be found in Table 4. The numbers presented are rounded median values (with the 5th and 95th percentiles) of the annual average over the 5 simulated years. Clinical and subclinical cases are always at quarter level.

In the basic strategy (Basic3), we observed 42 clinical cases (median) per year, ranging from 33 to 51 cases for the 5th and 95th percentiles, respectively (Table 4). These cases led to a median 123 treatment days per year. We noted another 136 subclinical cases (median), and 16 cows with a high SCC or a history of IMI were culled (median). The median yearly income in the Basic3 strategy was €187,666 (Table 4).

Comparable numbers for clinical cases and culled cows could be observed when the high-producing cows were treated for $5 \mathrm{~d}$ instead of 3 (Longer), but with 
Table 3. Values used in the sensitivity analyses [default values (Tables 1 and 2) are marked by an asterisk]

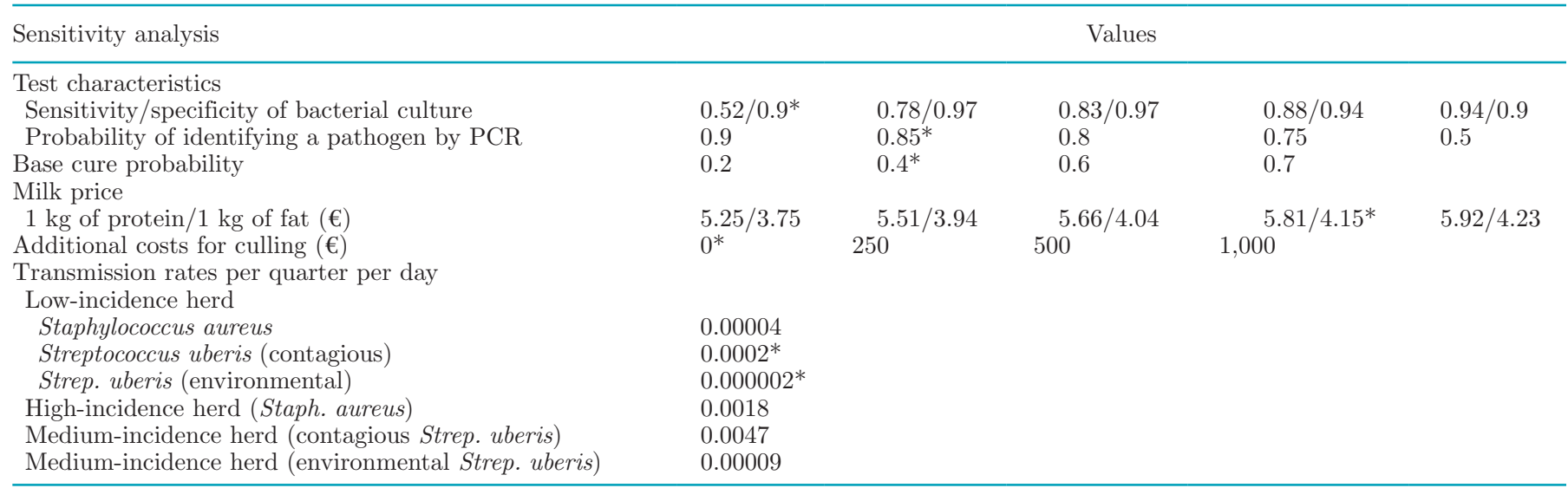

a higher median and variance in treatment days. The median number of subclinical cases was lower, with a higher variance skewed to the left (Table 4). If all cows were treated for $5 \mathrm{~d}$ (Basic5), the median number of clinical cases and of subclinical cases was lower and the median number of treatment days increased. The number of culled cows was slightly lower (Table 4). The median yearly income remained similar across these strategies (Table 4).

For the Repeated strategy, in which cows with multiple clinical IMI cases were culled, the number of clinical cases resembled the number of clinical cases in Basic5, but with fewer treatment days and more culled cows, including cows culled in relation to IMI intervention (Table 4). In all other strategies that included reactive culling, we found fewer clinical cases, with the smallest median of 29 cases in the Before75 strategy. The numbers of subclinical cases in the Repeated and After strategies were higher than in Basic5, but lower than in Basic3 and Longer. All other strategies that included culling showed fewer subclinical cases, with the smallest median of 106 in the Before75 strategy. All culling strategies had a larger number of culled cows than the strategies without culling as an intervention, up to a median of 32 cows culled per year in the Before75 strategy. In addition, the median number of treatment days was lower, with a minimum of 7 treatment days (median) in the Before75 strategy. In general, a higher number of treatment days corresponded to fewer culled cows; an exception was the strategy After, which resulted in more treatment days and more culled cows than the strategy Repeated (Table 4). The median yearly income in the Repeated and After strategies was around €191,500. In the strategies Before50, Before75, notCullPregnant, and notCullTop, yearly income varied from $€ 195,600$ (notCullPregnant) to $€ 197,576$ (Before75).

Table 4. Median model output (with 5th and 95th percentiles) of 500 iterations for a herd with 200 dairy cows, simulated over 5 yr: net income (in $€$, income from milk minus costs related to IMI and feeding), number of clinical IMI cases, number of subclinical IMI cases, number of treatment days, and number of culled cows (due to IMI intervention, or with a high SCC or history of IMI) ${ }^{1}$

\begin{tabular}{|c|c|c|c|c|c|c|c|c|c|c|}
\hline \multirow{2}{*}{$\frac{\text { Strategy }}{\text { Basic3 }}$} & \multicolumn{2}{|c|}{ Net income $(€)$} & \multicolumn{2}{|c|}{$\begin{array}{l}\text { Clinical } \\
\text { IMI cases }\end{array}$} & \multicolumn{2}{|c|}{$\begin{array}{l}\text { Subclinical } \\
\text { IMI cases }\end{array}$} & \multicolumn{2}{|c|}{$\begin{array}{c}\text { Treatment } \\
\text { days }\end{array}$} & \multicolumn{2}{|c|}{$\begin{array}{l}\text { Culled } \\
\text { cows }\end{array}$} \\
\hline & 187,666 & $(173,363 ; 202,147)$ & 42 & $(33 ; 51)$ & 136 & $(121 ; 161)$ & 123 & $(95 ; 151)$ & 16 & $(12 ; 20)$ \\
\hline Basic5 & 190,014 & $(175,823 ; 205,741)$ & 37 & $(19 ; 46)$ & 123 & $(86 ; 145)$ & 179 & $(93 ; 220)$ & 15 & $(11 ; 18)$ \\
\hline Repeated & 191,280 & $(179,588 ; 205,338)$ & 38 & $(21 ; 46)$ & 125 & $(90 ; 145)$ & 86 & $(53 ; 106)$ & 20 & $(14 ; 25)$ \\
\hline After & 191,699 & $(179,990 ; 207,164)$ & 35 & $(15 ; 43)$ & 129 & $(80 ; 147)$ & 101 & $(46 ; 125)$ & 22 & $(13 ; 27)$ \\
\hline Before 50 & 196,995 & $(181,427 ; 211,492)$ & 30 & $(15 ; 38)$ & 111 & $(75 ; 130)$ & 47 & $(36 ; 64)$ & 24 & $(10 ; 29)$ \\
\hline notCullPregnant & 195,600 & $(184,007 ; 210,633)$ & 31 & $(14 ; 37)$ & 112 & $(74 ; 123)$ & 24 & $(12 ; 32)$ & 30 & $(17 ; 35)$ \\
\hline
\end{tabular}

${ }^{1}$ All values refer to the annual means over 5 simulated years and numbers are rounded to whole euro. The simulated strategies were Basic3 (all clinical cases were treated for $3 \mathrm{~d}$ with antibiotics, default strategy), Basic5 (all clinical cases were treated for $5 \mathrm{~d}$ ), Longer [high-producing cows (top 25\%) were treated for $5 \mathrm{~d}$ instead of $3 \mathrm{~d}$ ], Repeated (cows with repeated clinical cases were culled instead of being treated), After (cows were tested $7 \mathrm{~d}$ after treatment, still infected cows were culled), Before50 (cows were tested before treatment and cows with a cure probability below $50 \%$ were culled instead of treated), Before75 (similar to Before 50 , but cows with a cure probability below $75 \%$ were culled), notCullTop [similar to Before75, but high-producing cows (top 25\%) were exempt from culling], notCullPregnant [similar to Before75, but pregnant cows (at least $4 \mathrm{mo}$ ) were exempt from culling]. 

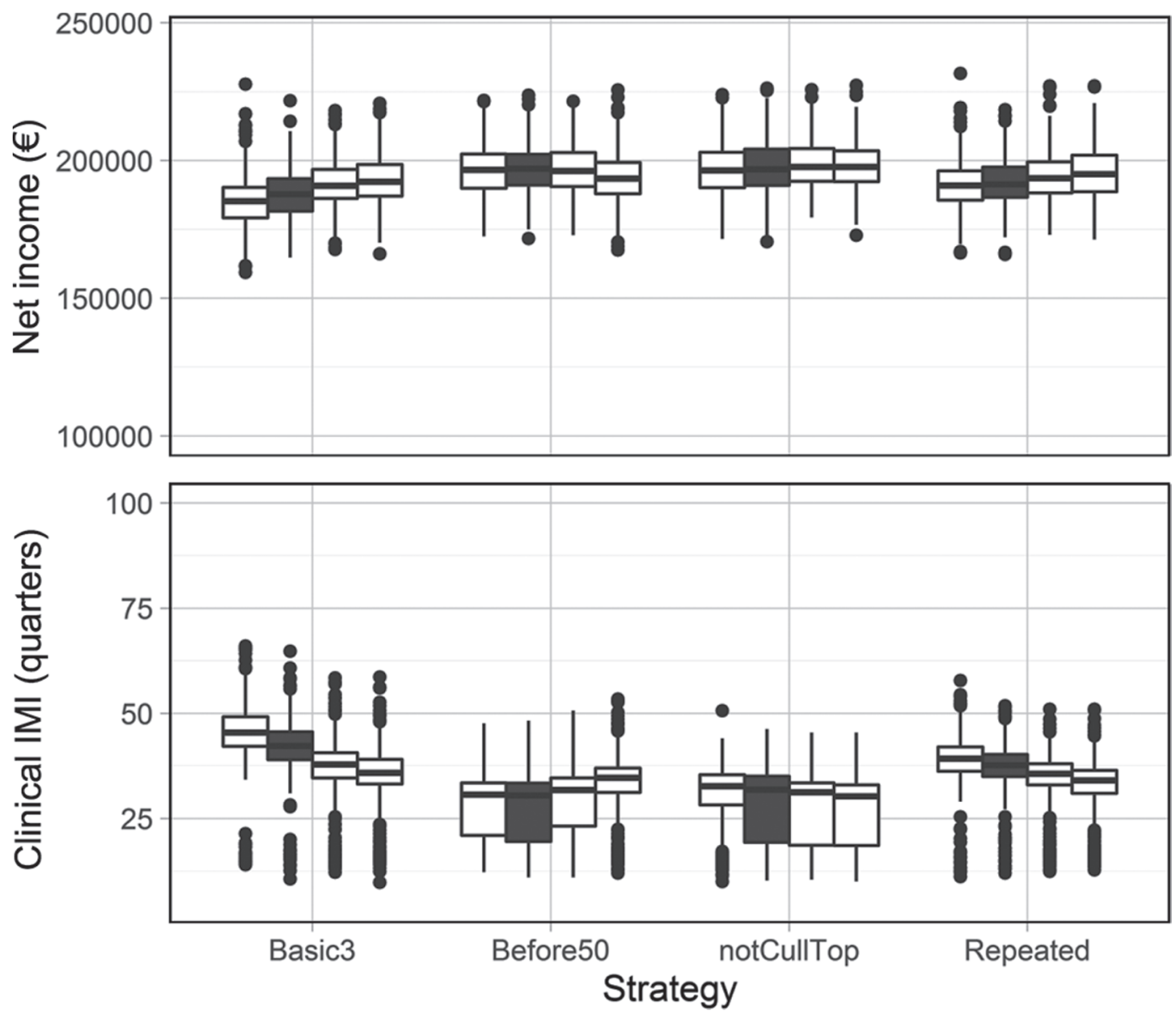

Figure 1. Results of the sensitivity analysis for the base cure rates in selected strategies (increasing cure rates from left to right, Table 3 ). Box plots show yearly income (income from milk minus costs for IMI intervention, dry cow treatment, feed, and culling) and yearly cumulative clinical IMI incidence for 500 iterations. Grey boxes show results with default values. The mean over the simulated 5-yr period was used for each iteration. The boxes show the lower and upper quartiles and the median (mid line). The whiskers show the lower and upper values in 1.5 interquartile range of the lower and upper quartiles. The dots show outliers. The selected strategies are Basic3 (all clinical cases were treated for $3 \mathrm{~d}$ with antibiotics, default strategy), Repeated (cows with repeated clinical cases were culled instead of being treated), Before50 (cows were tested before treatment and cows with a cure probability below $50 \%$ were culled instead of treated), and notCullTop [similar to Before50, but cows with a cure probability of less than $75 \%$ were culled, with high-producing cows (top $25 \%$ ) being exempt from culling].

Sensitivity analysis (see Table 3 for input values) on test characteristics showed that varying the probability of identifying the pathogen by PCR before treatment did not lead to considerable changes in the results. The income did not change substantially when increasing sensitivity (thus decreasing specificity) for bacterial culture in the After strategy, whereas the number of clinical IMI cases and treatment days per year decreased (Supplemental Figure S1; https://doi.org/10 $.3168 /$ jds.2018-14939).

An increased base cure probability after treatment led to increased income and a decreased number of clinical IMI, treatment days, and culled cows in all strategies, though the effect was less apparent in strategies where cows were tested and culled before treatment. In the Before50 strategy, the number of clinical IMI and treatment days increased with increasing base cure probability (Figure 1).

Sensitivity analysis for the fat and protein prices (Danish prices from 2017) showed that yearly income is highly dependent on the milk price, with medians ranging from €120,597 to €200,096 in the Basic3 strategy. Other strategies showed a similar pattern in the relationship between milk price and yearly income (Supplemental Figure S2; https://doi.org/10.3168/jds .2018-14939).

When culling was more expensive, the yearly income was lower. This effect was more pronounced in strategies with a larger number of culled cows (Supplemental Figure S3; https://doi.org/10.3168/jds.2018-14939). This led to greater discrepancies in yearly income among the different intervention strategies. 

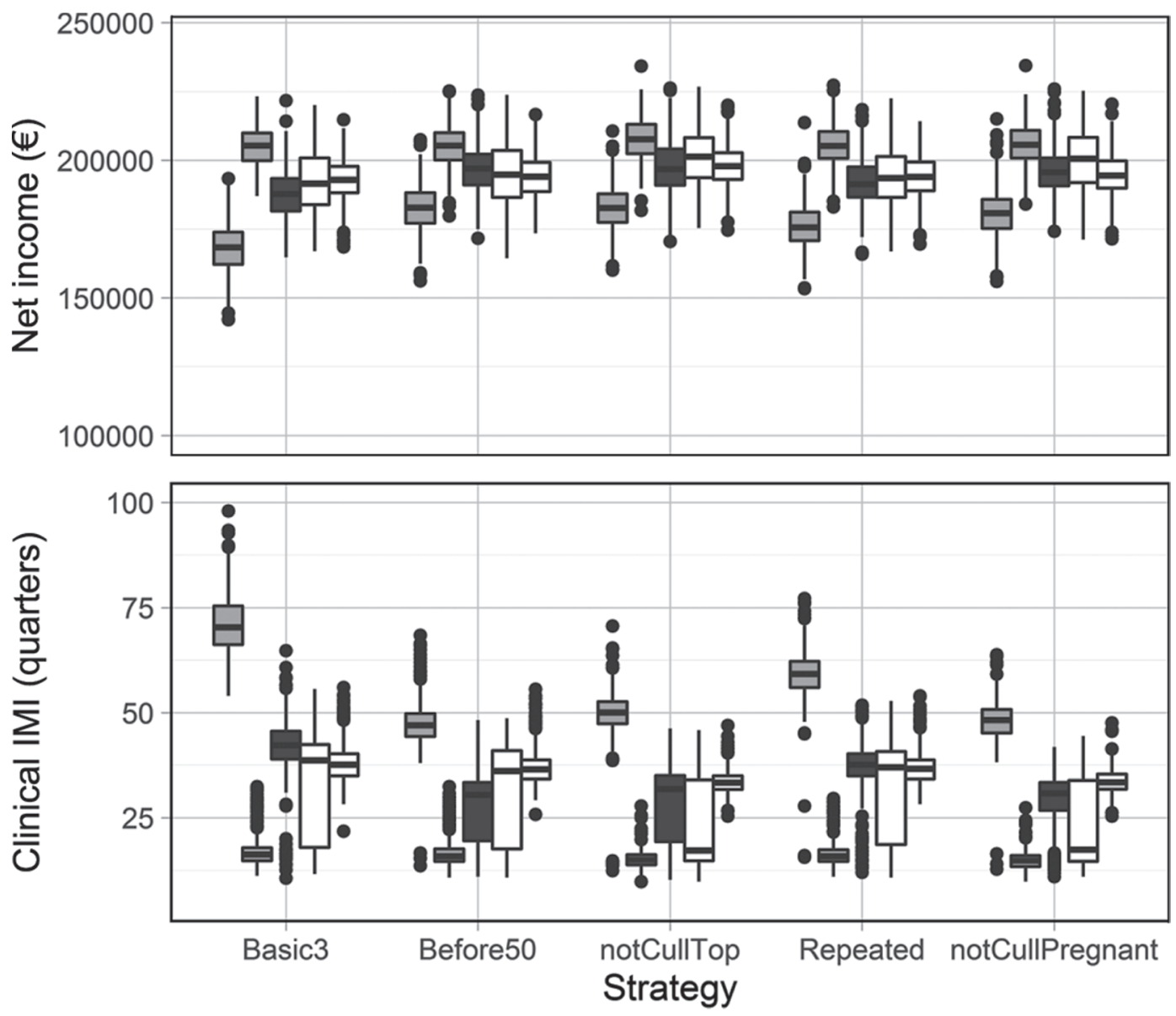

Figure 2. Results of the sensitivity analysis for transmission rate (light gray; left is low transmission rate, right is high transmission rate of Staphylococcus aureus, Table 3) and main causative pathogens (white; left is contagious Streptococcus uberis, right is environmental Strep. uberis, Table 3). Box plots show yearly income (income from milk minus costs for IMI intervention, dry cow treatment, feed, and culling) and yearly cumulative clinical IMI incidence for 500 iterations. Dark gray boxes show results with default values (Table 2). The mean over the simulated 5 -yr period was used for each iteration. The boxes show the lower and upper quartiles and the median (mid line). The whiskers show the lower and upper values in the 1.5 interquartile range of the lower and upper quartiles. The dots show outliers. The presented strategies are Basic3 (all clinical cases were treated for $3 \mathrm{~d}$ with antibiotics, default strategy), Repeated (cows with repeated clinical cases were culled instead of being treated), Before 50 (cows were tested before treatment and cows with a cure probability below $50 \%$ were culled instead of treated), notCullTop [similar to Before 50 , but cows with a cure probability of less than $75 \%$ were culled, with high-producing cows (top $25 \%$ ) being exempt from culling], and notCullPregnant (similar to notCullTop, but pregnant cows instead of high-producing cows were exempt from culling).

Sensitivity analyses for transmission rates led to varying cumulative clinical incidences. When a herd with a default median cumulative clinical incidence of around $19 \%$ was modeled, and in which most cases were caused by an environmental Strep. uberis strain, results showed a similar trend, albeit less pronounced (Figure 2). If most cases were caused by a contagious Strep. uberis strain, differences were more noticeable (Figure 2 ); for example, the variation in the results was higher. Furthermore, in the strategies Before75 (results not shown), notCullPregnant, and notCullTop, the median number of clinical cases and culled cows were lower, but the range of results was comparable. Similar to the environmental strain, the contagious Strep. uberis strain led to a higher number of clinical cases and a lower median yearly income in the Before50 strategy. In the other strategies, the median yearly income was higher for both Strep. uberis strains.

Results for a herd with a lower (8\%) median cumulative clinical incidence can be seen in Figure 2. In a herd with a low number of clinical cases, the yearly income was higher and differences across the various intervention strategies were smaller. In contrast, in a herd with a higher (35\%) median cumulative clinical incidence, in which most cases were caused by Staph. aureus, the income was lower and the differences among strategies were larger. For such a herd, the cumulative clinical incidence could be reduced to a median of $22 \%$ through the intervention strategy Before75 (results not shown), which also substantially reduced the number of 
treatment days. However, $23 \%$ of the cows were culled for reasons related to IMI (results not shown).

\section{DISCUSSION}

The objective of our study was to evaluate different intervention strategies for clinical IMI. Nine strategies were presented in the study. The default strategy (Basic3) included no reactive culling and all clinical cases were given intramammary treatment for $3 \mathrm{~d}$. Two strategies reflected interventions with increased antibiotic use (Basic5, Longer). Six interventions explicitly included reactive culling as an intervention for IMI, where decisions to cull or treat cows with clinical IMI were made at the individual animal level: culling instead of treatment (Before50, Before75, notCullTop, notCullPregnant, and Repeated) or for cows that were not cured (After).

Although some previous studies have investigated IMI intervention and culling in relation to clinical IMI (Halasa, 2012; Heikkilä et al., 2012; Cha et al., 2014), culling as a strategy, as presented in the current study, has rarely been considered as a reactive measure (Halasa and Hogeveen, 2018). Furthermore, in other IMI intervention studies, IMI transmission was seldom taken into account. In the present study, we modeled both IMI transmission and interventions, allowing for an evaluation of the long-term effects of the different strategies. Another novel aspect of the current study is that both economic and epidemiological consequences are presented as output. Farmers are not only interested in farm economics, but also in other perceived benefits (Valeeva et al., 2007; Jansen and Lam, 2012). Clinical IMI cases are perceived as both cost- and time-intensive (Jansen et al., 2009), and presenting the number of clinical cases alongside the economic implications could provide farmers with different incentives to adopt a new strategy. The number of treatment days and cows culled in relation to IMI are also shown to give an estimate of antibiotic use and longevity, which may affect the choice of an intervention strategy.

Our results showed that economically (based on yearly income), all strategies seemed more successful than the default 3-d intramammary treatment for all clinical cases (Basic3). Using more antibiotics (Basic5, Longer) led to only a small increase in yearly income (around $€ 2,000$ more median net income, Basic5), whereas the increase was higher in intervention strategies with reactive culling (around $€ 8,000$ to $€ 10,000$ more median net income with strategies Before50, Before75, notCullTop, and notCullPregnant). Testing new clinically affected quarters and subsequent cow-specific treatment or culling decisions (Before50, Before75, notCullTop, and notCullPregnant) led to a higher income than testing a week after treatment (After) or culling cows with repeated cases (Repeated). These results are not consistent with an earlier study that found cow-specific treatment was not economically beneficial (Steeneveld et al., 2011); however, that study did not model IMI transmission. By including transmission in our study, we were able to take into account the reduction in the number of IMI cases due to an intervention strategy and thus explain the higher yearly income, consistent with the findings of Halasa (2012).

Increasing the sensitivity of bacterial culture resulted in fewer cases (Supplemental Figure S1; https://doi.org/ 10.3168/jds.2018-14939). This is in accordance with the results of van den Borne et al. (2010), who showed that the sensitivity of the test to detect subclinical IMI had a substantial effect on the cost-effectiveness of control strategies. The results were also sensitive to the cure (Figure 1) and transmission rates (Figure 2), which is consistent with studies by Halasa (2012) and Down et al. (2013). Unfortunately, few studies have estimated the transmission rates of a small number of IMI-causing pathogens. Further studies with a focus on assessing the effect of control strategies on the transmission of IMI-causing pathogens are therefore required. This would allow a more precise assessment of the costeffectiveness of IMI control in dairy herds.

Sensitivity analysis for the cost of culling showed that income decreased with increasing culling costs (Supplemental Figure S3; https://doi.org/10.3168/jds.2018 -14939); the opposite was true for increased milk prices (Supplemental Figure S2; https://doi.org/10.3168/jds .2018-14939). Increased culling costs or reduced milk prices may therefore also have a substantial effect on the cost-effectiveness of an intervention strategy, and these factors should be taken into account when deciding which intervention strategy to adopt, especially if reactive culling is considered. It is important to mention that we had fixed prices over time. Although we acknowledge that this is unrealistic, it is not only difficult to predict changes in prices, but fixing a price also removes extra noise that would make it more challenging to compare different strategies.

Sensitivity analysis for the transmission rate of the main causative pathogen showed that adopting an intervention strategy for clinical IMI was not in itself sufficient to reach a herd incidence that was sufficiently low and stable to be comparable to a scenario with low transmission due to good hygiene (see Figure 2). Very few studies have investigated the effect of hygiene measures. Lam et al. (1996) investigated the effect of postmilking teat disinfection and found that it reduced the transmission rate noticeably. Huijps et al. (2010) estimated the costs and effects of various individual hygiene measures, though not in terms of transmission 
rates. Due to the lack of studies investigating the effect of a comprehensive hygiene strategy on the transmission rate of IMI pathogens within a herd, we did not include the costs arising from such a strategy to reduce transmission in the current study; this made it difficult to properly assess the cost-effectiveness of such a strategy. Nevertheless, considerable profit was seen when reducing the transmission rate (Figure 2), though it remains to be seen whether the economic gain would be enough to improve herd hygiene enough to reach the assumed lower transmission rate. Even so, from an epidemiological point of view, improving hygiene led to better results than a higher use of antibiotics or more culling.

Our results showed 3 ways to improve the IMI situation (i.e., reduce the number of not only clinical but also subclinical quarter cases) within a herd compared with the default scenario of 3-d intramammary treatment for all clinical quarters. The first was to increase the use of antimicrobials to treat clinical IMI cases (Basic5). Where this is not desirable, an alternative would be to cull reactively (After, Repeated, Before50, Before75, notCullTop, and notCullPregnant). In this case, antibiotic treatment could be greatly reduced but the number of cows culled in relation to IMI increased. Choosing between these 2 options could be seen as a decision between an increased risk of antimicrobial resistance (more antibiotics) or decreased longevity (more culling).

From an economic point of view, culling seemed to be the better choice in the studied herd with a medium cumulative clinical incidence. However, for a high cumulative clinical incidence, the distinction was not as clear and depended on the individual culling strategies (Figure 2), whereas it was nearly indiscernible when the cumulative clinical incidence was low (Figure 2). Furthermore, the sensitivity analysis showed that the economic advantage of reactive culling could be negated by culling costs that exceeded a certain amount, and in this case costs caused by a high culling rate could not be counteracted by the increased income from milk.

The third option, reducing the transmission level in the herd through other means (e.g., hygiene or biosecurity), was the only possible way to decrease IMI cases, antibiotic treatment, and IMI-related culling simultaneously. This option was not included in the investigated strategies, as information about costs and effects of various hygiene measures are not readily available, as described above.

The choice of approach should also depend on the specific herd and situation, as different intervention strategies may be preferable depending on the main causative pathogen strain. The decision has to be taken by the farmer, who must decide which option fits best with their beliefs or ideas for the herd.

We did not consider nonantibiotic treatment for IMI in the current study. To investigate this possibility, the model would also have to include a distinction between mild, moderate, and severe clinical IMI cases, as nonantibiotic treatments are mainly considered for mild or moderate clinical IMI (McDougall et al., 2009, 2016). This could be considered in future studies.

In addition, some of the strategies presented in the current paper involved strict culling rules to which farmers may not want to adhere. For that reason, we considered strategies in which groups of animals were excluded from culling, such as cows that were more than approximately $4 \mathrm{mo}$ pregnant (notCullPregnant) or high-producing cows (notCullTop). The latter strategy in particular considers an earlier study on determinants for antimicrobial treatment, in which high-producing cows were more likely to be treated in some Danish herds (Gussmann et al., 2018a).

We also simulated other strategies, including a higher probability of heifers being treated; however, the results were quite similar to some of the other strategies, so they were not presented here. Nevertheless, Vaarst et al. (2006) found farmers are willing to adopt a culling strategy matching their goal for the herd, so including some form of reactive culling in IMI intervention strategies is not unreasonable. However, this kind of culling affects the usual culling procedure, especially considering that we modeled a closed herd for which replacement heifers had to be available on-site. This may lead to problems when a larger number of animals are culled due to other, nonvoluntary reasons, such as other diseases. However, we concentrated on IMI interventions and their economic and epidemiological effects, leaving further investigations into culling dynamics as a whole for future studies.

\section{CONCLUSIONS}

We showed that cow-specific intervention strategies for IMI (including reactive culling) can be economically beneficial in the long term, even more so than a strategy with increased antibiotic treatment. The increased income from milk, together with the reduced number of IMI cases, compensated for the extra intervention costs, though economic benefits also depended on the transmission level in the herd. In addition, only 1 strategy could not reduce the number of clinical cases compared with the default 3-d intramammary treatment. The incidence was decreased either at the cost of an increased use of antibiotics or at the cost of the number of cows culled in relation to IMI. Therefore, the 
farmer has to choose the right balance between treatment and culling for a specific herd, taking into account their antimicrobial usage and longevity goals, as well as the main causative pathogen in the herd. We have shown that cow-specific treatment or culling decisions will, in most cases, reduce the incidence of clinical IMI while increasing income in the long term. The best option to achieve a stable and low number of IMI cases would be to reduce IMI transmission, but assessing the cost-effectiveness of this strategy is challenging due to a lack of data.

\section{ACKNOWLEDGMENTS}

The authors thank Tine van Werven (Department of Farm Animal Health, Utrecht University, Utrecht, the Netherlands) for her input in discussing interventions for clinical mastitis and her suggestions for additional intervention strategies. This study is part of the STOPMAST project funded by the Danish Milk Levy Foundation (Mælkeafgiftsfonden, Århus, Denmark), and part of the EMCo-Mast project funded by the Green Development and Demonstration Program (GUDP, Copenhagen, Denmark) under the Danish Directorate for Food, Fisheries and Agriculture, grant no. 34009-15-0918.

\section{REFERENCES}

Allore, H. G., L. W. Schruben, H. N. Erb, and P. A. Oltenacu. 1998 Design and validation of a dynamic discrete event stochastic simulation model of mastitis control in dairy herds. J. Dairy Sci. 81:703-717. https://doi.org/10.3168/jds.S0022-0302(98)75626-7.

Bar, D., L. W. Tauer, G. Bennett, R. N. Gonzales, J. A. Hertl, Y. H Schukken, H. F. Schulte, F. L. Welcome, and Y. T. Gröhn. 2008. The cost of generic clinical mastitis in dairy cows as estimated by using dynamic programming. J. Dairy Sci. 91:2205-2214. https:// doi.org/10.3168/jds.2007-0573.

Broom, D. M. 1991. Animal welfare: Concepts and measurement. J. Anim. Sci. 69:4167-4175.

Cederlöf, S. E., N. Toft, B. Aalbæk, and I. C. Klaas. 2012. Latent class analysis of the diagnostic characteristics of PCR and conventional bacteriological culture in diagnosing intramammary infections caused by Staphylococcus aureus in dairy cows at dry off. Acta Vet. Scand. 54:65. https://doi.org/10.1186/1751-0147-54-65.

Cha, E., A. R. Kristensen, J. A. Hertl, Y. H. Schukken, L. W. Tauer, F. L. Welcome, and Y. T. Gröhn. 2014. Optimal insemination and replacement decisions to minimize the cost of pathogen-specific clinical mastitis in dairy cows. J. Dairy Sci. 97:2101-2117. https:/ /doi.org/10.3168/jds.2013-7067.

Danish Integrated Antimicrobial Resistance Monitoring and Research Programme (DANMAP). 2016. DANMAP 2016-Use of antimicrobial agents and occurrence of antimicrobial resistance in bacteria from food animals, food and humans in Denmark. Accessed Jan. 17, 2018. http://www.danmap.org/ /media/Projekt \%20sites/Danmap/DANMAP\%20reports/DANMAP\%202016/ DANMAP_2016_web.ashx.

Down, P. M., M. J. Green, and C. D. Hudson. 2013. Rate of transmission: A major determinant of the cost of clinical mastitis. J. Dairy Sci. 96:6301-6314. https://doi.org/10.3168/jds.2012-6470.

EMA (European Medicines Agency) and EFSA (European Food Safety Authority). 2017. EMA and EFSA joint scientific opinion on measures to reduce the need to use antimicrobial agents in animal husbandry in the European Union, and the resulting impacts on food safety (RONAFA). EFSA J. 15. https://doi.org/10.2903/j .efsa.2017.4666.

Græsbøll, K., C. Kirkeby, S. S. Nielsen, T. Halasa, N. Toft, and L. E. Christiansen. 2016. Models to estimate lactation curves of milk yield and somatic cell count in dairy cows at the herd level for the use in simulations and predictive models. Front. Vet. Sci. 3:115. https://doi.org/10.3389/fvets.2016.00115.

Græsbøll, K., C. Kirkeby, S. S. Nielsen, T. Halasa, N. Toft, and L. E. Christiansen. 2017. A robust statistical model to predict the future value of the milk production of dairy cows using herd recording data. Front. Vet. Sci. 4:13. https://doi.org/10.3389/fvets .2017 .00013

Gröhn, Y. T., D. J. Wilson, R. N. González, J. A. Hertl, H. Schulte, G. Bennett, and Y. H. Schukken. 2004. Effect of pathogen-specific clinical mastitis on milk yield in dairy cows. J. Dairy Sci. 87:3358 3374. https://doi.org/10.3168/jds.S0022-0302(04)73472-4.

Gussmann, M., K. Græsbøll, N. Toft, S. S. Nielsen, M. Farre, C. Kirkeby, and T. Halasa. 2018a. Determinants of antimicrobial treatment for udder health in Danish dairy cattle herds. J. Dairy Sci. 101:505-517. https://doi.org/10.3168/jds.2017-12994.

Gussmann, M., C. Kirkeby, K. Græsbøll, M. Farre, and T. Halasa. 2018b. A strain-, cow-, and herd-specific bio-economic simulation model of intramammary infections in dairy cattle herds. J. Theor. Biol. https://doi.org/10.1016/j.jtbi.2018.04.022.

Hagnestam-Nielsen, C., and S. Østergaard. 2009. Economic impact of clinical mastitis in a dairy herd assessed by stochastic simulation using different methods to model yield losses. Animal 3:315-328. https://doi.org/10.1017/S1751731108003352.

Halasa, T. 2012. Bioeconomic modeling of intervention against clinical mastitis caused by contagious pathogens. J. Dairy Sci. 95:57405749. https://doi.org/10.3168/jds.2012-5470.

Halasa, T., and H. Hogeveen. 2018. Culling cows with mastitis: an economic perspective. Pages 79-90 in Natl. Mastitis Counc. 57th Annual Mtg. Proc., Tucson, AZ. Natl. Mastitis Counc., New Prague, $\mathrm{MN}$.

Halasa, T., K. Huijps, O. Østerås, and H. Hogeveen. 2007. Economic effects of bovine mastitis and mastitis management: A review. Vet. Q. 29:18-31. https://doi.org/10.1080/01652176.2007.9695224.

Halasa, T., M. Nielen, R. B. M. Huirne, and H. Hogeveen. 2009a. Stochastic bio-economic model of bovine intramammary infection. Livest. Sci. 124:295-305. https://doi.org/10.1016/j.livsci.2009.02 .019 .

Halasa, T., M. Nielen, T. van Werven, and H. Hogeveen. 2010. A simulation model to calculate costs and benefits of dry period interventions in dairy cattle. Livest. Sci. 129:80-87. https://doi.org/ 10.1016/j.livsci.2010.01.009.

Halasa, T., O. Østerås, T. van Werven, H. Hogeveen, and M. Nielen. 2009b. Meta-analysis of dry cow management for dairy cattle. Part 1: Protection against new intramammary infections. J. Dairy Sci. 92:3134-3149. https://doi.org/10.3168/jds.2008-1740.

Heikkilä, A.-M., J. I. Nousiainen, and S. Pyörälä. 2012. Costs of clinical mastitis with special reference to premature culling. J. Dairy Sci. 95:139-150. https://doi.org/10.3168/jds.2011-4321.

Hertl, J. A., Y. H. Schukken, F. L. Welcome, L. W. Tauer, and Y. T. Gröhn. 2014. Pathogen-specific effects on milk yield in repeated clinical mastitis episodes in Holstein dairy cows. J. Dairy Sci. 97:1465-1480. https://doi.org/10.3168/jds.2013-7266.

Hortet, P., F. Beaudeau, H. Seegers, and C. Fourichon. 1999. Reduction in milk yield associated with somatic cell counts up to 600000 cells $/ \mathrm{ml}$ in French Holstein cows without clinical mastitis. Livest. Prod. Sci. 61:33-42. https://doi.org/10.1016/S0301-6226(99)00051 -2 .

Huijps, K., H. Hogeveen, T. J. G. M. Lam, and A. G. J. M. Oude Lansink. 2010. Costs and efficacy of management measures to improve udder health on Dutch dairy farms. J. Dairy Sci. 93:115-124. https://doi.org/10.3168/jds.2009-2412.

Jansen, J., and T. J. G. M. Lam. 2012. The role of communication in improving udder health. Vet. Clin. North Am. Food Anim. Pract. 28:363-379. https://doi.org/10.1016/j.cvfa.2012.03.003. 
Jansen, J., B. H. P. van den Borne, R. J. Renes, G. van Schaik, T. J. G. M. Lam, and C. Leeuwis. 2009. Explaining mastitis incidence in Dutch dairy farming: The influence of farmers' attitudes and behaviour. Prev. Vet. Med. 92:210-223. https://doi.org/10.1016/j prevetmed.2009.08.015.

Kirkeby, C., K. Græsbøll, S. S. Nielsen, L. E. Christiansen, N. Toft, E. Rattenborg, and T. Halasa. 2016. Simulating the epidemiological and economic impact of paratuberculosis control actions in dairy cattle. Front. Vet. Sci. 3:90. https://doi.org/10.3389/fvets .2016 .00090 .

Kirkeby, C., T. Halasa, M. Gussmann, N. Toft, and K. Græsbøll. 2017. Methods for estimating disease transmission rates: Evaluating the precision of Poisson regression and two novel methods. Sci. Rep. 7:9496. https://doi.org/10.1038/s41598-017-09209-x.

Kudahl, A. B., J. T. Sørensen, S. S. Nielsen, and S. Østergaard. 2007. Simulated economic effects of improving the sensitivity of a diagnostic test in paratuberculosis control. Prev. Vet. Med. 78:118-129. https://doi.org/10.1016/j.prevetmed.2006.10.004.

Lam, T. J. G. M., M. C. M. Dejong, Y. H. Schukken, and A. Brand. 1996. Mathematical modeling to estimate efficacy of postmilking teat disinfection in split-udder trials of dairy cows. J. Dairy Sci. 79:62-70.

Mahmmod, Y. S., N. Toft, J. Katholm, C. Grønbæk, and I. C. Klaas. 2013. Bayesian estimation of test characteristics of real-time PCR, bacteriological culture and California mastitis test for diagnosis of intramammary infections with Staphylococcus aureus in dairy cattle at routine milk recordings. Prev. Vet. Med. 112:309-317. https://doi.org/10.1016/j.prevetmed.2013.07.021.

McDougall, S., E. Abbeloos, S. Piepers, A. S. Rao, S. Astiz, T. van Werven, J. Statham, and N. Pérez-Villalobos. 2016. Addition of meloxicam to the treatment of clinical mastitis improves subsequent reproductive performance. J. Dairy Sci. 99:2026-2042. https: //doi.org/10.3168/jds.2015-9615.

McDougall, S., M. A. Bryan, and R. M. Tiddy. 2009. Effect of treatment with the nonsteroidal antiinflammatory meloxicam on milk production, somatic cell count, probability of re-treatment, and culling of dairy cows with mild clinical mastitis. J. Dairy Sci. 92:4421-4431. https://doi.org/10.3168/jds.2009-2284.

Østergaard, S., M. G. G. Chagunda, N. C. Friggens, T. W. Bennedsgaard, and I. C. Klaas. 2005. A stochastic model simulating pathogen-specific mastitis control in a dairy herd. J. Dairy Sci. 88:42434257. https://doi.org/10.3168/jds.S0022-0302(05)73111-8.

R Core Team. 2015. R: A language and environment for statistical computing. Vienna. Accessed Aug. 14, 2015. https://www.r -project.org/.
Ruegg, P. L. 2003. Practical food safety interventions for dairy production. J. Dairy Sci. 86(E. Suppl.):E1-E9. https://doi.org/10.3168/ jds.S0022-0302(03)74034-X.

Schepers, A. J., T. J. G. M. Lam, Y. H. Schukken, J. B. M. Wilmink, and W. J. A. Hanekamp. 1997. Estimation of variance components for somatic cell counts to determine thresholds for uninfected quarters. J. Dairy Sci. 80:1833-1840.

Steeneveld, W., T. van Werven, H. W. Barkema, and H. Hogeveen. 2011. Cow-specific treatment of clinical mastitis: An economic approach. J. Dairy Sci. 94:174-188. https://doi.org/10.3168/jds.2010 $-3367$.

Taponen, S., L. Salmikivi, H. Simojoki, M. T. Koskinen, and S. Pyörälä. 2009. Real-time polymerase chain reaction-based identification of bacteria in milk samples from bovine clinical mastitis with no growth in conventional culturing. J. Dairy Sci. 92:26102617. https://doi.org/10.3168/jds.2008-1729.

Vaarst, M., T. W. Bennedsgaard, I. Klaas, T. B. Nissen, S. M. Thamsborg, and S. Østergaard. 2006. Development and daily management of an explicit strategy of nonuse of antimicrobial drugs in twelve Danish organic dairy herds. J. Dairy Sci. 89:1842-1853.

Valeeva, N. I., T. J. G. M. Lam, and H. Hogeveen. 2007. Motivation of dairy farmers to improve mastitis management. J. Dairy Sci. 90:4466-4477. https://doi.org/10.3168/jds.2007-0095.

van den Borne, B. H. P., G. van Schaik, T. J. G. M. Lam, and M. Nielen. 2010. Therapeutic effects of antimicrobial treatment during lactation of recently acquired bovine subclinical mastitis: Two linked randomized field trials. J. Dairy Sci. 93:218-233. https:// doi.org/10.3168/jds.2009-2567.

von Keyserlingk, M. A. G., J. Rushen, A. M. de Passillé, and D. M. Weary. 2009. Invited review: The welfare of dairy cattle - Key concepts and the role of science. J. Dairy Sci. 92:4101-4111. https:// doi.org/10.3168/jds.2009-2326.

Wickham, H. 2009. ggplot2: Elegant Graphics for Data Analysis. Springer International Publishing, New York, NY.

Wilson, D. J., R. N. Gonzalez, and H. H. Das. 1997. Bovine mastitis pathogens in New York and Pennsylvania: Prevalence and effects on somatic cell count and milk production. J. Dairy Sci. 80:2592-2598.

Zadoks, R. N., H. G. Allore, H. W. Barkema, O. C. Sampimon, G. J. Wellenberg, Y. T. Gröhn, and Y. H. Schukken. 2001. Cow- and quarter-level risk factors for Streptococcus uberis and Staphylococcus aureus mastitis. J. Dairy Sci. 84:2649-2663. https://doi.org/10 .3168/jds.S0022-0302(01)74719-4. 